УДК 616.895.8:575.174.015.3

Для цитирования: Тигунцев В.В., Петрова В.Н., Семке А.В., Сорокина В.А., Платонов Д.Г. Полиморфные варианты генов триптофангидроксилазы не ассоциированы с шизофренией и её ведущей симптоматикой. Сибирский вестник психиатрии и наркологии. 2018; 1 (98): 18-23. https://doi.org/10.26617/1810-3111-2018-1(98)-18-23

\title{
Полиморфные варианты генов триптофрангидроксилазы не ассоциированы с шизофренией и её ведущей симптоматикой
}

\section{Тигунцев В.В. ${ }^{1}$, Петрова В.Н. ${ }^{2}$, Семке А.В. ${ }^{1}$, Сорокина В.А. ${ }^{3}$, Платонов Д.Г. ${ }^{3}$}

${ }^{1}$ НИИ психического здоровья, Томский национальный исследовательский медицинский иентр Российской академии наук Россия, 634014, Томск, ул. Алеутская, 4

${ }^{2}$ Томская областная клиническая психиатрическая больница

Россия, 634014, Томск, ул. Алеутская, 4

${ }^{3}$ Кемеровская областная клиническая психиатрическая больница

Россия, 650036, Кемерово, ул. Волгоградская, 41

\section{PEЗЮME}

Введение. Большая часть симптомов шизофрении может быть разделена на две крупные категории: позитивные и негативные. В отличие от позитивной симптоматики негативная симптоматика зачастую считается необратимой и свидетельствует о глубоком поражении психики. Одними из генов-кандидатов предрасположенности к шизофрении рассматриваются гены триптофангидроксилазы TPHI и TPH2, ключевого фермента биосинтеза серотонина. Изучение вклада полиморфных вариантов генов $T P H 1$ и $T P H 2$ в развитие шизофрении и ведущей симптоматики заболевания в славянской популяции Томской и Кемеровской областей. Методы. Было обследовано 468 этнически русских пациентов с параноидной и простой формами шизофрении. ДНК из венозной крови выделялась фенол-хлороформным микрометодом. Для исследования было выбрано 3 полиморфных варианта в гене TPHI (rs1800532, rs7933505, rs684302) и 4 полиморфных варианта в гене TPH2 (rs7305115, rs4290270, rs1386494, rs1487278). Генотипирование проводилось на амплификаторе "RealtimeStepOnePlus". Распределение частот генотипов по исследованным полиморфным локусам проверяли на соответствие равновесию Харди-Вайнберга с помощью критерия $\chi^{2}$. Различия считались достоверными при уровне значимости р <0,05. Результаты. Частотный анализ в контрольной и исследуемой группах не выявил значимых различий, как и в подгруппах больных с ведущей позитивной и негативной симптоматикой. Заключение. Исследованные полиморфизмы не вносят значимого вклада в развитие шизофрении и её ведущей симптоматики в славянской популяции Томской и Кемеровской областей.

\section{Ключевые слова: шизофрения, триптофангидроксилаза, генетика, полиморфизм, серотонин.}

\section{ВВЕДЕНИЕ}

Шизофрения - тяжёлое психиатрическое расстройство, частота встречаемости которого составляет примерно $1 \%$ населения планеты, характеризуется нарушением социального функционирования, адаптационных процессов и высоким уровнем инвалидизации [1;2]. Это заболевание имеет мультифакториальную природу, важную часть которой составляет генетическая компонента. Риск развития шизофрении и других психических заболеваний у родственников больных значительно превосходит средний в популяции. Было найдено множество геновкандидатов, потенциально принимающих участие в развитии шизофрении, и подавляющее большинство из них вносят вклад в развитие и формирование нервной системы, а также систем нейротрансмиттеров (дофаминергической, серотонинергической, глутаматергической и др.) [3-6].

Шизофрению отличают прогрессирующие и зачастую необратимые изменения личности. Большая часть симптомов шизофрении может быть разделена на две крупные категории: позитивные и негативные. К позитивной симптоматике относятся галлюцинации, бред, психомоторное возбуждение, сверхценные и навязчивые идеи. Негативные симптомы подразумевают ущерб здоровой психике, исчезновение какой-либо её способности. К данной симп- томатике относятся утрата интеллекта (слабоумие), памяти (амнезия), способности испытывать яркие эмоции (апатия).

Серотонин (5-гидрокситриптамин, 5-НТТ) один из основных нейромедиаторов центральной нервной системы. При его участии реализуются агрессия, депрессивное сексуальное и пищевое поведение, восприятие боли, активность некоторых гормонов [7-9]. Серотониновая система тесно связана с контролем других нейромедиаторных систем, в частности моноаминовой и ГАМК-ергической [10]. Понижение количества серотонина в мозге одна из биохимических причин возникновения депрессии, тревожных состояний, импульсивности и суицидальных тенденций. При повышении концентрации серотонина могут наблюдаться диссоциативные расстройства [10].

Триптофангидроксилаза (ТРН) - ключевой фермент первой стадии биосинтеза серотонина, катализирует присоединение ОН-группы к триптофану, превращая его в 5-гидрокситриптофан [11]. Показано, что существуют 2 изоформы триптофангидроксилазы: ТРН1 и ТРН2, кодируемые генами ТPH1 (11p15) и ТРН2 (12q21.1) соответственно [12]. В мозге функционирует вторая изоформа фермента, первая изоформа экспрессируется в эпифизе, периферических тканях и тучных клетках [12]. 
Исследование вклада полиморфных вариантов генов триптофангидроксилазы в развитие шизофрении проводилось в основном в странах Азии, где $T P H 1$ и TPH2 рассматривались как гены-кандидаты наследственной предрасположенности к шизофрении и ведущей её симптоматике. Полиморфный вариант rs1800532 (А218C) генаТРН1, согласно метаанализу с использованием базы данных SZGene [13], показал стойкую эпидемиологическую достоверность вклада в развитие шизофрении. В 2012 г. в Китае было проведено исследование регуляторных участков гена TPH2, которое обнаружило значительные различия в частотах аллелей и генотипов между группами контроля и больных параноидной шизофренией по полиморфному варианту rs4570625 (-703G/T) искомого гена [14]: аллель G чаще встречался в опытной группе. Задолго до этого, в 2000 г., японские исследователи во главе с Т. Shinkai выявили взаимосвязь полиморфного варианта А779С в гене TPHI с негативной симптоматикой у мужчин, больных шизофренией [15].

Однако большинство публикаций, представленных в базе данных Pubmed, не выявили значимого вклада генов триптофангидроксилазы в патогенез обозначенного расстройства.

Так, в той же Японии не было обнаружено ассоциации между полиморфизмами обозначенных генов с шизофренией $[16 ; 17]$, так же как и в работах исследователей из Италии [18] и Кореи [7; 19].

Одно из немногих исследований полиморфных вариантов генов ТPH в отношении населения России проводилось в НЦПЗ РАМН в 2009 г., однако опытную группу в нём составили пациенты с расстройствами шизофренического спектра. В этой выборке помимо шизофрении установленными диагнозами были шизоаффективный психоз и первый психотический эпизод. Таким образом, не ставилось цели установить взаимосвязь полиморфизмов с конкретной нозологией группы эндогенных психозов. Р.В. Ефимов и др. [20] выявили предрасполагающий эффект аллеля А полиморфного варианта А218C (rs1800532) гена TPH1 к развитию обозначенной группы расстройств, что может свидетельствовать о возможном вкладе генов TPH в патогенез конкретно шизофрении у населения России.

Целью данного исследования является изучение вклада полиморфных вариантов генов TPH1 и TPH2 в развитие шизофрении и ведущей симптоматики заболевания в славянской популяции Сибирского региона.

\section{МАТЕРИАЛЫ И МЕТОДЫ}

Исследование проводилось в соответствии с требованиями Хельсинкской декларации Всемирной медицинской ассоциации об этических принципах проведения медицинских исследований с участием людей в качестве субъектов.

Критериями включения больных в исследуемую группу являлись: установленный диагноз шизофрении (F20), добровольное согласие на участие в исследовании.
Критериями исключения из исследования были: наличие коморбидных неврологических и соматических заболеваний, затрудняющих объективную оценку клинического состояния, вызванного основным психиатрическим заболеванием; отказ больного от участия в исследовании.

Проводилась стандартизация группы по возрасту, длительности заболевания и ведущей симптоматике (позитивной или негативной).

Нами обследовано 468 этнически русских пациентов с диагностированной параноидной и простой шизофренией, находившихся на стационарном лечении в ОГБУЗ «Томская клиническая психиатрическая больница» (главный врач - С.М. Андреев), в клиниках НИИ психического здоровья (главный врач д.м.н. В.Ф. Лебедева) и в ГКУЗ КО «Кемеровская областная клиническая психиатрическая больница» (главный врач - к.м.н. В.А. Сорокина). В исследование вошло 236 (52,9\%) женщин и 232 $(47,1 \%)$ мужчины, средний возраст составил 41,8 $\pm 13,6$ года (от 18 до 77 лет включительно). Протокол исследования был одобрен независимым локальным Комитетом по этике НИИ психического здоровья Томского НИМЦ. Пациенты были информированы о характере исследования и его целях, были получены письменные информированные согласия. Контрольная группа была представлена 127 психически и соматически здоровыми добровольцами (средний возраст составил 38,5+13,2 года).

В качестве материала для экспериментального исследования была использована венозная кровь. Венозную кровь брали из локтевой вены в период c 8.00 до 9.00 натощак в пробирки фирмы BD Vacutainer с антикоагулянтом ЭДТА. Полученную кровь использовали для выделения ДНК фенолхлороформным микрометодом.

На основании литературных данных для исследования было выбрано 3 полиморфных варианта в гене TPHI (rs1800532, rs7933505, rs684302) и 4 полиморфных варианта в гене ТРН2 (rs7305115, rs4290270, rs1386494, rs1487278), которые ранее были исследованы на предмет ассоциаций с шизофренией или с другими психическими заболеваниями, в чей патогенез вовлекалась дисфункция серотонинергической нейропередачи. Генотипирование проводилось на амплификаторе "RealtimeStepOnePlus” (США). ПЦР проводили в 96луночных планшетах в объеме 5 мкл на амплификаторе "Real-timeStepOnePlus" (США) в присутствии 10 нг геномной ДНК-матрицы и смеси ПЦРпраймеров.

Статистическая обработка результатов проводилась при помощи программы SPSS 20.0. Распределение частот генотипов по исследованным полиморфным локусам проверяли на соответствие равновесию Харди-Вайнберга и выполняли с помощью критерия $\chi^{2}$. Сравнение частот генотипов и аллелей в исследуемых группах проводили по критерию $\chi^{2}$. Различия считались достоверными при уровне значимости $\mathrm{p}<0,05$ [21]. 


\section{РЕЗУЛЬТАТЫ}

Сравнение частот генотипов в группах пациентов с шизофренией и контроля не выявило статистически значимых отличий (табл. 1).

После разделения пациентов по гендерному признаку и ведущей симптоматике было проведено сравнение частот генотипов в подгруппах с позитивными и негативными симптомами. Как у мужчин, так и у женщин не было выявлено статистиче- ски значимых различий частот генотипов в исследуемых подгруппах (табл. 2, 3).

Однако наблюдается тенденция к понижению частоты гетерозиготных генотипов по полиморфным вариантам rs1800532 и rs7933505 среди мужчин с преобладающей позитивной симптоматикой заболевания $(\mathrm{p}=0,07)$. Отношение шансов для этих генотипов составило 0,54 (95\% CI: $0,31-0,94)$ для rs 1800532 и 0,53 (95\% CI: 0,30-0,92) для rs7933505 соответственно.

Т а б л и ц 1

\begin{tabular}{|c|c|c|c|c|c|}
\hline \multicolumn{6}{|c|}{$\begin{array}{c}\text { Частоты встречаемости генотипов и аллелей полиморфных вариантов генов } T P H \\
\text { в группах пациентов с шизофренией и здоровых индивидов }\end{array}$} \\
\hline Полиморфный вариант гена & Генотип / аллель & Пациенты (n, \%) & Здоровые лица (n, \%) & $\chi^{2}$ & $\mathrm{p}$ \\
\hline \multirow[t]{3}{*}{$\mathrm{rs} 1800532(T P H 1)$} & $\mathrm{CC}$ & $142(30,1 \%)$ & $38(29,9 \%)$ & \multirow[t]{3}{*}{0,10} & \multirow[t]{3}{*}{0,95} \\
\hline & $\mathrm{CA}$ & $242(51,4 \%)$ & $64(50,4 \%)$ & & \\
\hline & AA & $87(18,5 \%)$ & $25(19,7 \%)$ & & \\
\hline \multirow[t]{3}{*}{ rs7933505 (TPH1) } & GG & $142(30,3 \%)$ & $38(29,9 \%)$ & \multirow[t]{3}{*}{0,12} & \multirow[t]{3}{*}{0,94} \\
\hline & AG & $241(51,4 \%)$ & $64(50,4 \%)$ & & \\
\hline & AA & $86(18,3 \%)$ & $25(19,7 \%)$ & & \\
\hline \multirow[t]{3}{*}{ rs684302(TPHI) } & TT & $288(71,3 \%)$ & $89(71,8 \%)$ & \multirow[t]{3}{*}{0,01} & \multirow[t]{3}{*}{$\overline{0,99}$} \\
\hline & TC & $116(28,7 \%)$ & $35(28,2 \%)$ & & \\
\hline & $\mathrm{CC}$ & $0(0 \%)$ & $0(0 \%)$ & & \\
\hline \multirow{3}{*}{ rs7305115 (TPH2) } & GG & $172(36,3 \%)$ & $38(30,2 \%)$ & \multirow[t]{3}{*}{1,87} & \multirow[t]{3}{*}{0,39} \\
\hline & $\mathrm{AG}$ & $226(47,7 \%)$ & $68(54 \%)$ & & \\
\hline & $\mathrm{AA}$ & $76(16 \%)$ & $20(15,9 \%)$ & & \\
\hline \multirow{3}{*}{ rs4290270 (TPH2) } & TT & $182(38,6 \%)$ & $40(31,5 \%)$ & \multirow[t]{3}{*}{2,58} & \multirow[t]{3}{*}{0,28} \\
\hline & AT & $223(47,2 \%)$ & $64(50,4 \%)$ & & \\
\hline & AA & $67(14,2 \%)$ & $23(18,1 \%)$ & & \\
\hline \multirow[t]{3}{*}{ rs1386494 (TPH2) } & GG & $357(75,3 \%)$ & $92(73 \%)$ & \multirow[t]{3}{*}{0,41} & \multirow[t]{3}{*}{0,81} \\
\hline & GA & $108(22,8 \%)$ & $32(25,4 \%)$ & & \\
\hline & AA & $9(1,9 \%)$ & $2(1,6 \%)$ & & \\
\hline \multirow[t]{3}{*}{ rs1487278 (TPH2) } & TT & $277(58,7 \%)$ & $71(55,9 \%)$ & \multirow[t]{3}{*}{0,32} & \multirow[t]{3}{*}{0,85} \\
\hline & CT & $171(36,2 \%)$ & $49(38,6 \%)$ & & \\
\hline & $\mathrm{CC}$ & $24(5,1 \%)$ & $7(5,5 \%)$ & & \\
\hline
\end{tabular}

П р и м е ч а н и е . p - Уровень статистической значимости различий параметров между группами пациентов с шизофренией и здоровыми лицами; $\chi^{2}$ - стандартный критерий Пирсона для сравнения частот генотипов генов, d.f.=2.

Т а б ли ц а 2

\begin{tabular}{|c|c|c|c|c|c|}
\hline \multicolumn{6}{|c|}{$\begin{array}{c}\text { Частоты встречаемости генотипов и аллелей полиморфных вариантов генов } T P H \\
\text { в группах мужчин с ведущей позитивной и негативной симптоматикой }\end{array}$} \\
\hline Полиморфный вариант гена & Генотип / аллель & $\mathrm{C} \ll+»$ симптомами $(\mathrm{n}, \%)$ & $\mathrm{C} \ll-»$ симптомами $(\mathrm{n}, \%)$ & $\chi^{2}$ & $\mathrm{p}$ \\
\hline \multirow[t]{3}{*}{ Rs1800532 (TPH1) } & $\mathrm{CC}$ & $40(36 \%)$ & $27(28,4 \%)$ & \multirow[t]{3}{*}{5,32} & \multirow[t]{3}{*}{$\frac{\mathrm{P}}{0,07}$} \\
\hline & $\mathrm{CA}$ & $52(46,8 \%)$ & $59(62,1 \%)$ & & \\
\hline & AA & $19(17,1 \%)$ & $9(9,5 \%)$ & & \\
\hline \multirow[t]{3}{*}{ Rs7933505 (TPH1) } & GG & $40(37 \%)$ & $27(28,4 \%)$ & \multirow[t]{3}{*}{5,46} & \multirow[t]{3}{*}{$0,0^{7}$} \\
\hline & $\mathrm{AG}$ & $50(46,3 \%)$ & $59(62,1 \%)$ & & \\
\hline & AA & $18(16,7 \%)$ & $9(9,5 \%)$ & & \\
\hline \multirow[t]{3}{*}{ Rs684302 (TPH1) } & TT & $63(63,6 \%)$ & $63(71,6 \%)$ & \multirow[t]{3}{*}{1,34} & \multirow[t]{3}{*}{0,51} \\
\hline & $\mathrm{TC}$ & $36(36,4 \%)$ & $25(28,4 \%)$ & & \\
\hline & $\mathrm{CC}$ & $0(0 \%)$ & $0(0 \%)$ & & \\
\hline \multirow[t]{3}{*}{ Rs7305115 (TPH2) } & GG & $38(33,6 \%)$ & $35(36,5 \%)$ & \multirow[t]{3}{*}{0,23} & \multirow[t]{3}{*}{0,89} \\
\hline & $\mathrm{AG}$ & $59(52,2 \%)$ & $47(49 \%)$ & & \\
\hline & AA & $16(14,2 \%)$ & $14(14,6 \%)$ & & \\
\hline \multirow[t]{3}{*}{ Rs4290270 (TPH2) } & TT & $41(36,9 \%)$ & $30(31,3 \%)$ & \multirow[t]{3}{*}{0,77} & \multirow[t]{3}{*}{0,68} \\
\hline & AT & $55(49,5 \%)$ & $51(53,1 \%)$ & & \\
\hline & $\mathrm{AA}$ & $15(13,5 \%)$ & $15(15,6 \%)$ & & \\
\hline \multirow[t]{3}{*}{ Rs1386494 (TPH2) } & GG & $82(72,6 \%)$ & $73(76 \%)$ & \multirow[t]{3}{*}{1,07} & \multirow[t]{3}{*}{0,51} \\
\hline & GA & $30(26,5 \%)$ & $23(24 \%)$ & & \\
\hline & AA & $1(0,9 \%)$ & $0(0 \%)$ & & \\
\hline \multirow[t]{3}{*}{ Rs1487278 (TPH2) } & TT & $61(55 \%)$ & $56(57,7 \%)$ & \multirow[t]{3}{*}{2,04} & \multirow[t]{3}{*}{0,36} \\
\hline & $\mathrm{CT}$ & $47(42,3 \%)$ & $35(36,1 \%)$ & & \\
\hline & $\mathrm{CC}$ & $3(2,7 \%)$ & $6(6,2 \%)$ & & \\
\hline
\end{tabular}

П р и м е ч а н и е . p - Уровень статистической значимости различий параметров между группами пациентов с ведущей позитивной и негативной симптоматикой; $\chi^{2}-$ стандартный критерий Пирсона для сравнения частот генотипов генов, d.f.=2. 


\begin{tabular}{|c|c|c|c|c|c|}
\hline \multicolumn{6}{|c|}{$\begin{array}{c}\text { Частоты встречаемости генотипов и аллелей полиморфных вариантов генов } T P H \\
\text { в группах женщин с ведущей позитивной и негативной симптоматикой }\end{array}$} \\
\hline Полиморфный вариант гена & Генотип / аллель & С «+» симптомами $(\mathrm{n}, \%)$ & С «-» симптомами $(\mathrm{n}, \%)$ & $\chi^{2}$ & $\mathrm{p}$ \\
\hline \multirow{3}{*}{ rs1800532 (TPHI) } & $\mathrm{CC}$ & $35(26,5 \%)$ & $22(26,2 \%)$ & \multirow{3}{*}{1,64} & \multirow{3}{*}{0,44} \\
\hline & $\mathrm{CA}$ & $66(50 \%)$ & $48(57,1 \%)$ & & \\
\hline & AA & $31(23,5 \%)$ & $14(16,7 \%)$ & & \\
\hline \multirow{3}{*}{ rs7933505 (TPH1) } & GG & $35(26,5 \%)$ & $22(25,9 \%)$ & \multirow{3}{*}{1,81} & \multirow{3}{*}{0,41} \\
\hline & AG & $66(50 \%)$ & $49(57,6 \%)$ & & \\
\hline & AA & $31(23,5 \%)$ & $14(16,5 \%)$ & & \\
\hline \multirow{3}{*}{ rs684302 (TPHI) } & TT & $85(78 \%)$ & $54(74 \%)$ & \multirow{3}{*}{0,39} & \multirow{3}{*}{0,82} \\
\hline & TC & $24(22 \%)$ & $19(26 \%)$ & & \\
\hline & $\mathrm{CC}$ & $0(0 \%)$ & $0(0 \%)$ & & \\
\hline \multirow{3}{*}{ rs7305115 (TPH2) } & GG & $46(34,8 \%)$ & $33(39,3 \%)$ & \multirow{3}{*}{0,96} & \multirow{3}{*}{0,62} \\
\hline & $\mathrm{AG}$ & $64(48,5 \%)$ & $35(41,7 \%)$ & & \\
\hline & AA & $22(16,7 \%)$ & $16(19 \%)$ & & \\
\hline \multirow{3}{*}{ rs4290270 (TPH2) } & TT & $52(39,4 \%)$ & $34(41 \%)$ & \multirow{3}{*}{0,16} & \multirow{3}{*}{0,92} \\
\hline & AT & $63(47,4 \%)$ & $37(44,6 \%)$ & & \\
\hline & AA & $18(13,5 \%)$ & $12(14,5 \%)$ & & \\
\hline \multirow{3}{*}{ rs1386494 (TPH2) } & GG & $100(75,8 \%)$ & $62(73,8 \%)$ & \multirow{3}{*}{1,01} & \multirow{3}{*}{0,6} \\
\hline & GA & $29(22 \%)$ & $18(21,4 \%)$ & & \\
\hline & AA & $3(2,3 \%)$ & $4(4,8 \%)$ & & \\
\hline \multirow{3}{*}{ rs1487278 (TPH2) } & TT & $76(57,1 \%)$ & $55(66,3 \%)$ & \multirow{3}{*}{4,62} & \multirow{3}{*}{0,1} \\
\hline & CT & $51(38,3 \%)$ & $21(25,3 \%)$ & & \\
\hline & $\mathrm{CC}$ & $6(4,5 \%)$ & $7(8,4 \%)$ & & \\
\hline
\end{tabular}

Примечание. $\mathrm{p}$ - Уровень статистической значимости различий параметров между группами пациентов с ведущей позитивной и негативной симптоматикой; $\chi^{2}-$ стандартный критерий Пирсона для сравнения частот генотипов генов, d.f.=2.

\section{ОБСУЖДЕНИЕ}

Данное исследование не выявило разницу в частотах генотипов по полиморфным вариантам генов триптофангидроксилазы между группами здоровых людей и больных шизофренией, а также между группами пациентов с ведущей позитивной и негативной симптоматикой. Нарушение содержания серотонина в мозге является важной составляющей патогенеза шизофрении, поэтому логично рассматривать гены, кодирующие ключевой фермент биосинтеза этого нейромедиатора, в качестве генов-кандидатов развития шизофрении и отдельных групп её симптомов. В России взаимосвязь генов ТРН и шизофрении исследовалась довольно слабо. К примеру, в публикации Р.В. Ефимова и др. [18] сообщается о вкладе полиморфного варианта гена TPHI в развитие расстройств шизофренического спектра в популяции Московской области. Этот факт не позволяет судить о вкладе гена в патогенез отдельной нозологической единицы, в частности шизофрении, однако дальнейшие исследования могли бы дать больше информации о влиянии исследуемых генов на развитие психических заболеваний в разных регионах России.

\section{ЗАКЛЮЧЕНИЕ}

Таким образом, исследованные полиморфизмы генов не вносят значимого вклада в развитие шизофрении и её ведущей симптоматики в славянской популяции Кемеровской и Томской областей.

\section{КОНФЛИКТ ИНТЕРЕСОВ}

Авторы заявляют об отсутствии конфликта интересов в связи с публикацией данной статьи.

\section{ИСТОЧНИК ФИНАНСИРОВАНИЯ}

Исследование выполнено при поддержке гранта РФФИ 17-29-06035 «Новые подходы к фармакогенетике антипсихотик-индуцированной гиперпролактинемии у больных шизофренией».

\section{СООТВЕТСТВИЕ ПРИНЦИПАМ ЭТИКИ}

Исследование проведено с соблюдением норм современной биомедицинской этики и этических стандартов, разработанным в соответствии с Хельсинской декларацией ВМА (протокол заседания этического комитета НИИ психического здоровья, Томский национальный исследовательский медицинский центр Российской академии наук № 3 от 06.04.2007).

\section{ЛИТЕРАТУРА}

1. Tandon R., Keshavan M.S., Nasrallah H.A. Schizophrenia, «just the facts» what we know in 2008. 2. Epidemiology and etiology. Schizophr. Res. 2008; 102 (1-3): 1-18.

2. Семке А.В., Ветлугина Т.П., Иванова С.А. и др. Биопсихосоциальные основы и адаптационно-компенсаторные механизмы шизофрении в регионе Сибири. Сибирский вестник психиатрии и наркологии. 2009; 5 (56): 15-20.

3. Федоренко О.Ю., Рудиков Е.В., Гаврилова В.А., Боярко Е.Г. и др. Ассоциация (N251S)-PIP5K2A с расстройствами шизофренического спектра: исследование русской популяции Сибири. Журнал неврологии и психиатрии им. С. С. Корсакова. 2013; 5: 58-61.

4. Pelov P., Teltsh O., Greenbaum L. et al. Involvement of PTPN5, the gene encoding the STriatal-Enriched protein tyrosine Phosphatase (STEP), in schizophrenia and cognition. Psychiatr Genet. 2012; 22(4): 168-176. doi: 10.1097/YPG.0b013e328351858

5. Голимбет В.Е. Генетика шизофрении. Журнал неврологии и психиатрии им. С.С. Корсакова. 2003; 103 (3): 58-67.

6. Henriksen M.G., Nordgaard J., Jansson L.B. Genetics of Schizophrenia: Overview of Methods, Findings and Limitations. Front Hum Neurosci. 2017; 11: 322. doi: 10.3389/fnhum.2017.00322

7. Serretti A., Chiesa A., Porcelli S. et al. Influence of TPH2 variants on diagnosis and response to treatment in patients with major depression, bipolar disorder and schizophrenia. Psychiatry Research. 2011; 189: 26-32.

8. Иванова С.А., Шмиголь М.В., Сандый-оол А.В. и др. Полиморфизм генов серотонинергической системы у детей и подростков тывинской популяции с расстройствами поведения. Сибирский вестник психиатрии и наркологии. 2011; 1 (64): 42-45.

9. Бохан Н.А., Иванова С.А., Левчук Л.А. Серотониновая система в модуляции депрессивного и агрессивного поведения. Томск: Издательство «Иван Федоров», 2013: 104. 
10. Левчук Л.А., Шмиголь М.В., Иванова С.А. Серотонинергическая система в патогенезе и терапии депрессивных расстройств (обзор литературы). Сибирский вестник психиатрии и наркологии. 2012; 2 (71): 75-79.

11. Fitzpatrick P.F. Tetrahydropterin dependent aminoacidhydroxylases. Annu Rev Biochem.1999; 68: 355-381.

12. Walther D.J., Peter J.U., Winter S. Serotonylation of small GTPases is a signal transduction pathway that triggers platelet alpha-granule release. Cell. 2003; 115 (7): 851-862.

13. Allen N.C., Bagade S., McQueen M.B. et al. Systematic metaanalyses and field synopsis of genetic association studies in schizophrenia: the SzGene database. Nat. Genet. 2008; 40 (7): 827-834. doi: $10.1038 / n g .171$

14. Xu X.M., Ding M., Pang H., Wang B.J. TPH2 gene polymorphisms in the regulatory region are associated with paranoid schizophrenia in Northern Han Chinese. Genet. Mol. Res. 2014; 13 (1): 1497-1507.

15. Shinkai T., Ohmori O., Suzuki T. et al. Polymorphisms of tryptophan hydroxylase gene and the symptomatology of schizophrenia: an association study. Psychiatr Genet. 2000; 10 (4) $165-171$.

16. Higashi S., Ohnuma T., Shibata N. No genetic association be- tween tryptophan hydroxylase 2 gene polymorphisms and Japanese schizophrenia. Psychiatr. Genet. 2007; 17 (2): 123. doi: 10.1097/YPG.0b013e328011c01a

17. Shiroiwa K., Hishimoto A., Mouri K. et al. Common genetic variations in TPH1/TPH2 genes are not associated with schizophrenia in Japanese population. Neurosci. Lett. 2010; 472 (3): 194-198.

18. Serretti A., Lilli R., Lorenzi C. Tryptophan hydroxylase gene and major psychoses. Psychiatry Res. 2001; 103 (1): 79-86.

19. Paik I., Toh K., Kim J., Lee C. TPH gene may be associated with suicidal behavior, but not with schizophrenia in the Korean population. Hum. Hered. 2000; 50 (6): 365-369.

20. Ефимов Р.В., Шавлюдова А.Ш., Голимбет В.Е. Ассоциация полиморфных маркеров гена триптофангидроксилазы (ТрН) с эндогенными психозами. Генетика. 2009; 45 (12): 16681673.

21. Гланц С. Медико-биологическая статистика. Москва: Практика, 1998: 459.

Поступила в редакцию 10.11.2017 Утверждена к печати 5.02.2018

Тигунцев Владимир Владимирович, очный аспирант.

Петрова Валерия Николаевна, заместитель главного врача по медицинской части.

Семке Аркадий Валентинович, д.м.н., профессор, заместитель директора по научной и лечебной работе, заведующий отделением эндогенных расстройств.

Сорокина Вероника Альбертовна, к.м.н., главный врач.

Платонов Дмитрий Геннадьевич, к.м.н., заместитель главного врача по медицинской части.

Тигунцев Владимир Владимирович, cristall2009@ live.ru

УДК 616.895.8:575.174.015.3

For citation: Tiguntsev V.V., Petrova V.N., Semke A.V., Sorokina V.A., Platonov D.G. There is no association of tryptophan hydroxylase gene polymorphisms with schizophrenia and its leading symptomatology. Siberian Herald of Psychiatry and Addiction Psychiatry. 2018, 1 (98): 18-23. https://doi.org/10.26617/1810-3111-2018-1(98)-18-23

\section{There is no association of tryptophan hydroxylase gene polymorphisms with schizophrenia and its leading symptomatology}

Tiguntsev V.V. ${ }^{1}$, Petrova V.N. ${ }^{2}$, Semke A.V. ${ }^{1}$, Sorokina V.A. ${ }^{3}$, Platonov D.G. ${ }^{3}$

${ }^{1}$ Mental Health Research Institute, Tomsk National Research Medical Center, Russian Academy of Sciences Aleutskaya Street 4, 634014, Tomsk, Russian Federation

${ }^{2}$ Tomsk Regional Clinical Psychiatric Hospital

Aleutskaya Street 4, 634014, Tomsk, Russian Federation

${ }^{3}$ Kemerovo Regional Clinical Psychiatric Hospital

Volgogradskaya Street 41, 650036, Kemerovo, Russian Federation

\section{ABSTRACT}

Most of the symptoms of schizophrenia can be divided into two major categories: positive and negative. Unlike positive, negative symptoms are often irreversible and give evidence of profound mental impairment. Genes TPH1 and TPH 2 of tryptophan hydroxylase, a key enzyme of serotonin biosynthesis, are considered as candidate genes predisposing to schizophrenia. Aim of the research is to study of the contribution of polymorphic variants of the TPH1 and $T P H 2$ genes to the development of schizophrenia and the leading symptomatology of the disease in the Caucasian population of the Tomsk and Kemerovo regions. Subjects and Methods. 468 ethnically Russian patients with paranoid and simple schizophrenia are examined. DNA from venous blood is isolated by a phenol-chloroform micromethod. For the study, 3 polymorphic variants are selected in the TPH1 gene (rs1800532, rs7933505, rs684302) and 4 polymorphic variants in the TPH2 gene (rs7305115, rs4290270, rs1386494, rs 1487278). Genotyping is carried out by "Real-time StepOnePlus" amplifier. The frequency distribution of the genotypes from the polymorphic loci examined is checked for compliance with the Hardy-Weinberg equilibrium using the $\chi^{2}$ criterion. Differences are considered reliable at a significance level of $p<0.05$. Results and Discussion. Frequency analysis in the control and study groups shows no significant differences, as in subgroups of patients with leading positive and negative symptoms. Conclusion. The investigated polymorphisms do not make a significant contribution to the development of schizophrenia and its leading symptomatology in the Caucasian population of the Tomsk and Kemerovo regions.

Keywords: schizophrenia, tryptophan hydroxylase, genetics, polymorphism, serotonin 


\section{REFERENCES}

1. Tandon R., Keshavan M.S., Nasrallah H.A. Schizophrenia, «just the facts» what we know in 2008. 2. Epidemiology and etiology. Schizophr. Res. 2008; 102 (1-3): 1-18.

2. Semke A.V., Vetlugina T.P., Ivanova S.A. i dr. Biopsihosocialnye osnovyi adaptacionno-kompensatornye mekhanizmy shizofrenii $\mathrm{v}$ regione Sibiri [Biopsychosocial bases and adaptivecompensator mechanisms of schizophrenia in region of Siberia]. Sibirskij vestnik psihiatri i inarkologii - Siberian Herald of Psychiatry and Addiction Psychiatry. 2009; 5 (56): 15-20 (in Russian).

3. Fedorenko O.Yu., Rudikov E.V., Gavrilova V.A., Boyarko I.G. dr. Associaciya (N251S)-PIP5K2A s rasstrojstvami shizofrenicheskogo spectra: issledovanie russkoj populyacii Sibiri [Association of (N251S)-PIP5K2A with schizophrenic disorders: a study of the Russian population of Siberia]. Zhurnal nevrologii I psihiatri iimeni S.S. Korsakova - Journal of Neurology and Psychiatry S.S. Korsakov. 2013; 5: 58-61 (in Russian).

4. Pelov P., Teltsh O., Greenbaum L. et al. Involvement of PTPN5, the gene encoding the STriatal-Enriched protein tyrosine Phosphatase (STEP), in schizophrenia and cognition. Psychiatr Genet. 2012; 22(4): 168-176. doi: 10.1097/YPG.0b013e328351858

5. Golimbet V.E. Genetika shizofrenii [Genetics of schizophrenia] Zhurnal nevrologii i psihiatrii imeni S.S. Korsakova - Journal of Neurology and Psychiatry. S.S. Korsakov. 2003; 3 (103): 58-67 (in Russian).

6. Henriksen M.G., Nordgaard J., Jansson L.B. Genetics of Schizophrenia: Overview of Methods, Findings and Limitations. Front Hum Neurosci. 2017; 11:322 doi: 10.3389/fnhum 2017.00322

7. Serretti A., Chiesa A., Porcelli S. et al. Influence of TPH2 variants on diagnosis and response to treatment in patients with major depression, bipolar disorder and schizophrenia. Psychiatry Research. 2011; 189: 26-32.

8. Ivanova S.A., Shmigol M.V., Sandyj-ool A.V. i dr. Polimorfizm genov serotoninergicheskoj sistemy $u$ detej i podrostkov tyvinskoj populyacii s rasstrojstvami povedeniya [Polymorphism of genes of the serotoninergic system in children and adolescents of the tyvin population with disorders of behavior]. Sibirskij vestnik psihiatri I inarkologii - Siberian Herald of Psychiatry and Addiction Psychiatry. 2011; 1 (64): 42-45 (in Russian).

9. Bokhan N.A., Ivanova S.A., Levchuk L.A. Serotoninovaya sistema $\mathrm{v}$ modulyacii depressivnogo i agressivnogo povedeniya [Serotonin system in modulation of depressive and aggressive behavior]. Tomsk: Ivan Fedorov, 2013: 103 (in Russian).

10. Levchuk L.A., Shmigol M.V., Ivanova S.A. Serotoninergicheskaya sistema $\mathrm{v}$ patogeneze i terapii depressivnyh rasstrojstv (obzor literatury) [Serotoninergic system in the patho- genesis and therapy of depressive disorders (literature review)]. Sibirskij vestnik psihiatri i inarkologii - Siberian Herald of Psychiatry and Addiction Psychiatry. 2012; 2 (71): 75-79 (in Russian).

11. Fitzpatrick P.F. Tetrahydropterin dependent aminoacidhydroxylases. Annu Rev Biochem.1999; 68: 355-381.

12. Walther D.J., Peter J.U., Winter S. Serotonylation of small GTPases is a signal transduction pathway that triggers platelet alpha-granule release. Cell. 2003; 115 (7): 851-862.

13. Allen N.C., Bagade S., McQueen M.B. et al. Systematic metaanalyses and field synopsis of genetic association studies in schizophrenia: the SzGene database. Nat. Genet. 2008; 40 (7): 827-834. doi: 10.1038/ng.171

14. Xu X.M., Ding M., Pang H., Wang B.J. TPH2 gene polymorphisms in the regulatory region are associated with paranoid schizophrenia in Northern Han Chinese. Genet. Mol. Res. 2014; 13 (1): 1497-1507.

15. Shinkai T., Ohmori O., Suzuki T. et al. Polymorphisms of tryptophan hydroxylase gene and the symptomatology of schizophrenia: an association study. Psychiatr Genet. 2000; 10 (4): 165-171.

16. Higashi S., Ohnuma T., Shibata N. No genetic association between tryptophan hydroxylase 2 gene polymorphisms and Japanese schizophrenia. Psychiatr. Genet. 2007; 17 (2): 123. doi: 10.1097/YPG.0b013e328011c01a

17. Shiroiwa K., Hishimoto A., Mouri K. et al. Common genetic variations in TPH1/TPH2 genes are not associated with schizophrenia in Japanese population. Neurosci. Lett. 2010; 472 (3): 194-198.

18. Serretti A., Lilli R., Lorenzi C. Tryptophan hydroxylase gene and major psychoses. Psychiatry Res. 2001; 103 (1): 79-86.

19. Paik I., Toh K., Kim J., Lee C. TPH gene may be associated with suicidal behavior, but not with schizophrenia in the Korean population. Hum. Hered. 2000; 50 (6): 365-369.

20. Efimov R.V., Shavlyudova A.Sh., Golimbet V.E. Associaciya polimorfnyh markerov gena triptofangidroksilazy (TpH) s ehndogennymi psihozami [Association of polymorphic markers of tryptophan hydroxylase gene $(\mathrm{TrH})$ with endogenous psychoses]. Genetika - Genetics. 2009; 45 (12): 1668-1673 (in Russian).

21. Glantz S. Mediko-biologicheskaya statistika [Biostatistica]. Moscow: Praktika, 1998: 459 (in Russian)

Received November 10.2017 Accepted February 5.2018

Tiguntsev Vladimir V., full-timel post-graduate student, Mental Health Research Institute, Tomsk National Research Medical Center, Russian Academy of Sciences, Tomsk, Russian Federation.

Petrova Valeria N., Deputy Chief Medical Officer, Tomsk Regional Clinical Psychiatric Hospital, Tomsk, Russian Federation.

Semke Arkady V., MD., Professor, Deputy Director for Scientific and Medical Work, Head of Endogenous Disorders Department, Mental Health Research Institute, Tomsk National Research Medical Center, Russian Academy of Sciences, Tomsk, Russian Federation.

Sorokina Veronica A., PhD., chief physician, Kemerovo Regional Clinical Psychiatric Hospital, Kemerovo, Russian Federation.

Platonov Dmitry G., PhD., Deputy Chief Medical Officer, Kemerovo Regional Clinical Psychiatric Hospital, Kemerovo, Russian Federation .

Tiguntsev Vladimir V., cristal12009@live.ru 